\title{
Geodetically estimated location and geometry of the fault plane involved in the 2018 Hokkaido Eastern Iburi earthquake
}

\author{
Tomokazu Kobayashi ${ }^{*}$, Kyonosuke Hayashi and Hiroshi Yarai
}

\begin{abstract}
By applying the InSAR method to ALOS-2 SAR data acquired before and after the 2018 Hokkaido Eastern Iburi earthquake, the ground displacement fields were successfully mapped. Ground deformation is distributed on the eastern side of an active fault, known as the Ishikari-Teichi-Toen fault zone (ITTFZ). Uplift of up to $7 \mathrm{~cm}$ is distributed throughout the source region, and eastward movement of up to $\sim \mathrm{cm}$ is widely observed on the eastern side of the source region. The fault model constructed by inverting InSAR and GNSS data under an assumption of a uniform slip on a rectangular fault plane shows reverse fault motion on a plane dipping eastward at $74^{\circ}$. The fault top is positioned around a depth of $15 \mathrm{~km}$, suggesting that the slip significantly occurs deeper than the typical seismogenic zone for the Japanese island. The fault plane is at a relatively high dip angle, and the shallow extension of the estimated fault plane does not connect to any known surface traces of the ITTFZ. This may suggest that the fault involved with the 2018 event is physically separated from the ITTFZ, or that the fault plane bends to a lower dip angle at a shallow crustal depth. The fault rupture area is located in a spatially inhomogeneous seismic velocity structure field and the main slip occurs at the western edge of a low Vp area which vertically thickens on the eastern side of the fault. This may suggest that the 2018 earthquake occurred at seismic velocity boundary. An estimate of Coulomb Failure Function change suggests that the static stress change due to the 2018 event can promote reverse fault slip on the southern part of the ITTFZ.
\end{abstract}

Keywords: 2018 Hokkaido Eastern Iburi earthquake, Crustal deformation, InSAR, Fault model

\section{Introduction}

An inland earthquake with a moment magnitude $\left(M_{\mathrm{w}}\right)$ of 6.6 occurred on September 6, 2018, in Hokkaido, Japan. The focal depth was estimated as $37 \mathrm{~km}$ (Japan Meteorological Agency (JMA) 2018a) which is much deeper than the typical seismogenic zone in the Japanese island $(\sim 15 \mathrm{~km})$. This may be due to the region's complex tectonic setting. The westward migration of the Kurile fore-arc sliver is caused by the oblique subduction of the Pacific Plate and has formed the Hidaka collision zone (Kimura 1986) (Fig. 1). The crust in this region is subjected to compressional stress due to the oblique subduction of the Pacific Plate (Terakawa and Matsu'ura

*Correspondence: kobayashi-t96dv@mlit.go.jp

Geospatial Information Authority of Japan, 1 Kitasato, Tsukuba, Ibaraki 305-0811, Japan
2010), which presumably culminates in the promotion of reverse fault slip. As a consequence of this collision process, complicated geological structures have developed (Iwasaki et al. 2004; Kita et al. 2012), and many eastward dipping thrust faults have formed on the western side of the Hidaka Mountains (Ito 2002).

The 2018 earthquake occurred on the western edge of the thrust fault system. It should be noted that an active fault zone, called the Ishikari-Teichi-Toen fault zone (ITTFZ), is located close to the source region (Headquarters for Earthquake Research Promotion, HERP, 2010) (Fig. 1). According to HERP (2010), the ITTFZ consists of two parts: the main part (hereafter called ITTFZ-M), which is indicated by red solid lines in Fig. 1, and the southern part (hereafter called ITTFZ-S), indicated by red dotted lines. The long-term earthquake probability for the ITTFZ-S within the next 30 years is estimated as 


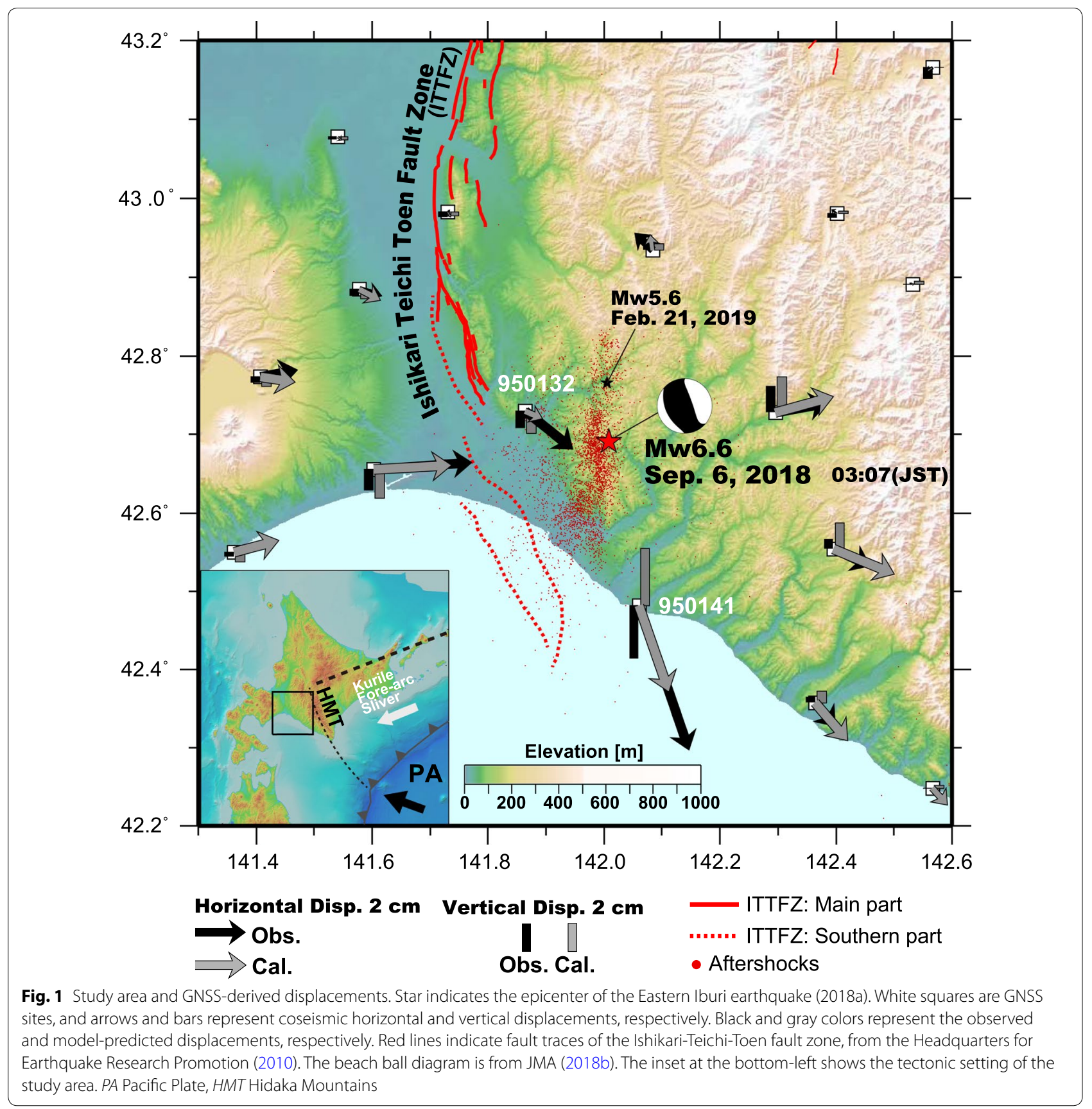

$0.2 \%$, which is relatively high compared to other active faults in Japan. The source region of the 2018 earthquake is located near the ITTFZ-S and the southern tip of the ITTFZ-M, thus it is a controversial point if the 2018 seismic event occurred as a part of the fault system of the ITTFZ or not. The detailed source properties of this seismic event are fundamental information needed to further discuss the relationship of this event to the regional tectonics.
An L-band synthetic aperture radar (SAR) satellite, known as the Advanced Land Observing Satellite 2 (ALOS-2), makes observations for the purpose of detecting crustal deformation using SAR interferometry (InSAR). InSAR data have often revealed the source properties of not only large earthquakes but also moderate-sized inland earthquakes with magnitudes of $\sim 6$ due to the high spatial resolution of the data (e.g., Kobayashi 2017; Kobayashi et al. 2017). InSAR is capable 
of detailed mapping of crustal deformation as a rapid response to a seismic event, which will provide information about the spatial features of the fault rupture. The primary purpose of this study is to rapidly report the rupture location and style of the Eastern Iburi earthquake by retrieving crustal deformation data, and to discuss its relationship to the region's seismo-tectonic setting.

\section{Data and analysis}

\section{SAR data and analysis method}

We used ALOS-2 data from three orbits (Additional file 1: Table S1) for calculation. These observations were all conducted in stripmap mode with a spatial resolution of $3 \mathrm{~m}$. To obtain the ground deformation, we applied an InSAR method to the data. Long spatial wavelength signals, which are presumably due to ionosphere-related noise, are included in the InSAR results. To reduce ionospheric noise, we applied a range split-spectrum method (Rosen et al. 2010; Gomba et al. 2016). We also reduced atmosphere-related noise using a numerical weather model; JMA mesoscale model (Kobayashi et al. 2014; Kobayashi 2016). The ALOS- 2 data were processed using the GSISAR software (Fujiwara and Tobita 1999; Fujiwara et al. 1999; Tobita et al. 1999; Tobita 2003). After data processing, we obtained three InSAR images (Additional file 2: Fig. S1a, S1d, and S1 g).

We obtained multiple independent displacement components of InSAR data, in which the microwaves are emitted from two opposing directions: from the eastern sky and the western sky. This allowed us to convert the derived displacements into two components, which are quasi-up-down (QUD) and quasi-east-west (QEW) components (Fujiwara et al. 2000). We used the two InSAR datasets depicted in Additional file 2: Fig. S1a and $\mathrm{S} 1 \mathrm{~g}$ for this analysis.

In addition to SAR-derived ground deformation data, we utilized data from the GNSS Earth Observation Network (GEONET) which has been deployed nationwide and is operated by the Geospatial Information Authority of Japan to obtain coseismic displacement vectors (Fig. 1) for the 2018 event. Note that the mounting pillars at two sites are tilted slightly as a result of the earthquake: sites 950132 (Atsuma) and 950141 (Monbetsu). The pillars are tilted with azimuth directions of $110^{\circ}$ for 950132 , and $200^{\circ}$ for 950141 . The azimuth is measured clockwise from north. The horizontal displacements caused by these inclinations were measured as $1.9 \mathrm{~cm}$ and $1.4 \mathrm{~cm}$ for 950132 and 950141, respectively. Thus, we corrected the coseismic displacements obtained from GNSS by subtracting the apparent displacements due to pillar inclinations at these two sites.

\section{Crustal deformation}

Figure 2 shows the estimated QUD and QEW components obtained from the InSAR data. In Fig. 2a, red and blue colors indicate uplift and subsidence, respectively. We can identify distinct uplift of up to $\sim 7 \mathrm{~cm}$, predominantly distributed in the source region. In contrast, the ground has subsided $\sim 2 \mathrm{~cm}$ on the western side of the source region where GNSS site 950132 is located. Figure $2 \mathrm{~b}$ shows the QEW field, where green and red colors indicate eastward and westward movements, respectively. There appears to be eastward movement on the eastern side of the source region of up to $\sim 4 \mathrm{~cm}$.

Some displacement discontinuities, indicated by arrows (Fig. 2b), can be observed in the QEW map, across which eastward and westward motions are located on the western and the eastern sides, respectively. In contrast, few clear discontinuities are found in QUD map. The details regarding these discontinuities are outside the scope of this study and will be discussed in Fujiwara et al. (2019).

Coseismic displacements were also recorded by GEONET deployed in and around the source region (Fig. 1), which agree with the spatial pattern we derived from the InSAR data. Note that it appears as though the displacement at site 950141 is opposite of the InSAR result: downward ground motion $(3.4 \mathrm{~cm})$ is visible within the uplift area. The amount is much larger than the downward movement resulting from the pillar inclination: $0.02 \mathrm{~mm}$. However, by zooming in on the QUD map (Additional file 3: Fig. S2), we can identify significant local subsidence in and around the GNSS site. It is possible that this site was affected by the local ground subsidence.

\section{Fault model with a uniform slip}

We constructed a fault model by assuming the presence of a rectangular fault with a uniform slip in an elastic half space (Okada 1985). We estimated the model parameters using a simulated annealing method, following the general procedure of Kobayashi et al. (2012). Taking into consideration the distribution of aftershocks (Fig. 1), the strike was searched from $-30^{\circ}$ to $+30^{\circ}$. For other parameters, we assigned search ranges of $141.8^{\circ}-142.2^{\circ}$ in longitude, $42.5^{\circ}-42.8^{\circ}$ in latitude, $0-50 \mathrm{~km}$ in depth, $0-20 \mathrm{~km}$ in length, $0-20 \mathrm{~km}$ in width, and $0-3 \mathrm{~m}$ in slip amount. Also, considering that the aftershock distribution is tilting downward to the east (HERP 2018), we have assumed an east-dipping in this model. Neither the dip angle nor the rake angle was constrained.

For the fault modeling, we used the three pairs of InSAR data (Additional file 2: Fig. S1). We calculated the variance of the displacement field outside the source region, where no deformation appeared, and regarded it 

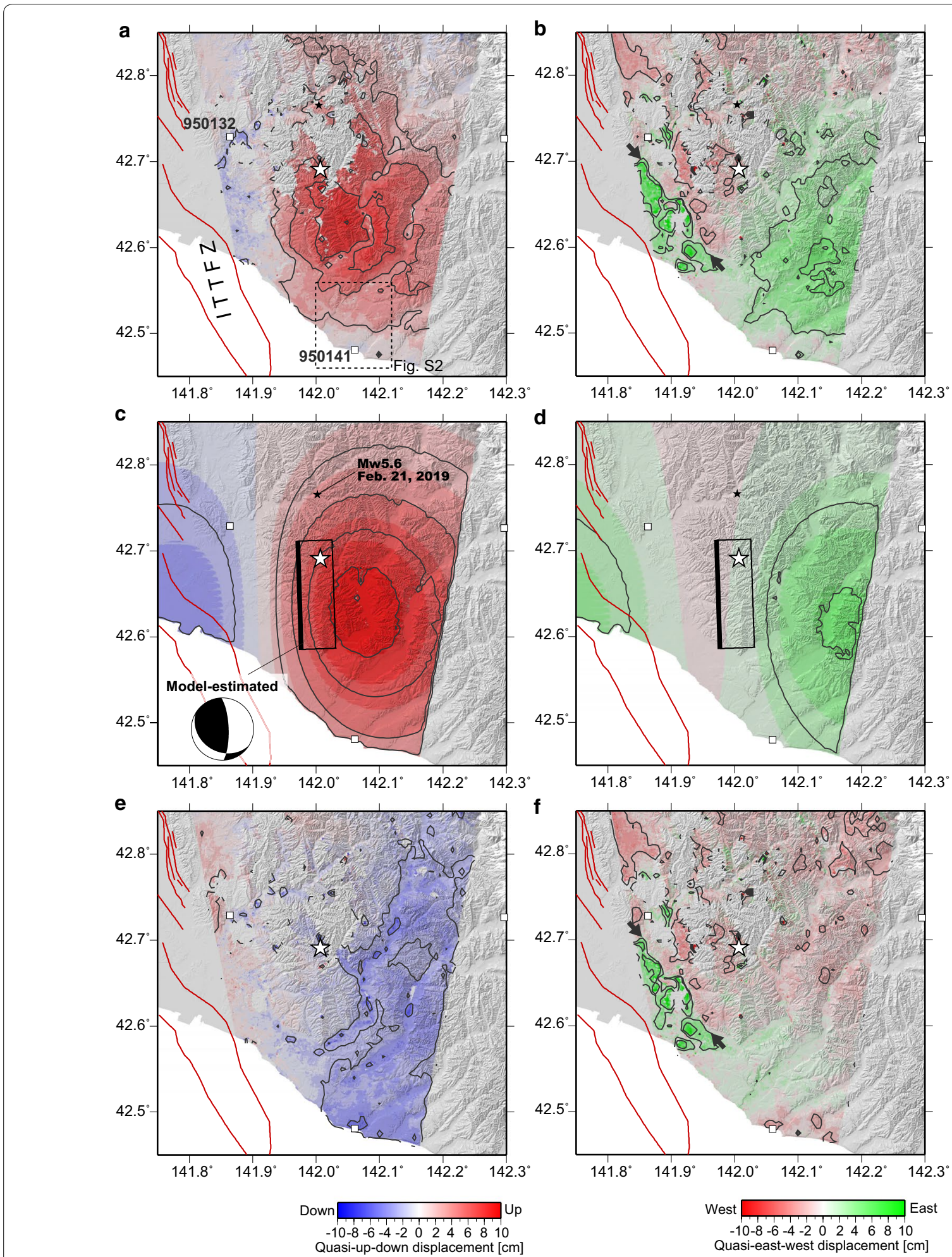

Fig. 2 a InSAR-derived displacements in a quasi-up-down component. The red and blue colors indicate uplift and subsidence, respectively. b A quasi-east-west component. The green and red colors indicate eastward and westward movements, respectively. c Model-predicted displacement for a quasi-up-down component. Black frame represents an estimated fault plane, projected on the ground. The beach ball diagram calculated from the estimated fault parameters is shown at the bottom-left. $\mathbf{d}$ Same as (c) but for a quasi-east-west component. e Residuals for a quasi-up-down component. f Same as (e) but for a quasi-east-west component 
as the variance for the study area. Consequently, for the weight, we assigned standard deviations of 2.1, 1.1, and $0.9 \mathrm{~cm}$ in line-of-site (LOS) component for InSAR paths 18,116 , and 122, respectively.

We also utilized GNSS data for our model, using standard deviations of the time series data for the weight: on average $0.2,0.3$, and $0.9 \mathrm{~cm}$ for E-W, N-S, and U-D components, respectively. Furthermore, we reduced the weight of sites 950132 and 950141 to suppress the local effect caused by the tilted pillars.

The fault parameters obtained from the model are listed in Table 1. Figure 2c, d shows the calculated displacements predicted from this model. Also, Additional file 2: Figure S1 shows the calculated LOS displacements predicted from this model. The residual reaches down to the background noise level. The GNSS data are also reproduced well (Fig. 1). Additional file 4: Figure S3 shows variations of the fault parameter estimates obtained from a bootstrap approach in order to recognize how well the estimates are constrained in the parameter searches. The modeled fault has a N-S orientation and a length of approximately $15 \mathrm{~km}$. The model shows that reverse fault motion is predominant. The fault plane dips to the east with a dip angle of $\sim 74^{\circ}$. The top and bottom of the fault are positioned at depths of $\sim 15 \mathrm{~km}$ and $\sim 30 \mathrm{~km}$, respectively. This is significantly deeper than the typical seismogenic zone for the Japanese island $(\sim 15 \mathrm{~km})$, as is the seismically determined focal depth $(37 \mathrm{~km})$. The slip area is mainly positioned at the south of the hypocenter. There is no slip at the hypocenter of largest aftershock that occurred on February 21, 2019, with $M_{\mathrm{w}}$ 5.6. The seismic moment is estimated to be $8.68 \times 10^{18} \mathrm{Nm}\left(M_{\mathrm{w}} 6.56\right)$, assuming a rigidity of $30 \mathrm{GPa}$. According to the results from JMA and National Research Institute for Earth Science and Disaster Resilience (NIED) CMT solutions, the total seismic moments are $1.08 \times 10^{19} \mathrm{Nm}\left(M_{\mathrm{w}} 6.6\right)$ and $1.00 \times 10^{19} \mathrm{Nm}\left(M_{\mathrm{w}} 6.6\right)$, respectively. The obtained result is in good agreement with the seismic analyses.

There is an obvious inconsistency for site 950141 between the observation and the model prediction: the vertical movement is not consistent between the data and the model. As mentioned previously, this area could have been subjected to not only fault-related crustal deformation but also local deformation. This local effect likely culminated in the bad data fitting.
The beach ball plot estimated from the fault model is shown in Fig. 2c, which is consistent with the seismically determined focal mechanism (Fig. 1), while seeing the details, non-double couple component is significantly included in the CMT solution. It may suggest that fault ruptures with a complex geometry system is involved with this seismic event rather than a single fault plane (Himematsu and Furuya 2016; Kobayashi 2017) although there is no clear signal suggesting the complexity in the geodetic data.

\section{Discussion}

\section{The source fault's association with the ITTFZ}

The known surface traces of the ITTFZ are located near the source region, thus whether or not the 2018 event was associated with the ITTFZ is one of fundamental questions in understanding of this earthquake. In this study, we investigated the spatial relationship between the two. First, we confirm the reliability of the estimated fault position with comparing to the aftershock distribution. The aftershocks from the 2018 event were distributed along a dipping angle to the east (Fig. 3c). Although the dipping angle of the aftershock distribution is similar to that of our fault model (Fig. 3c), there is an obvious difference in the horizontal positions between the two. With this in mind, how accurately can we determine the fault's position from the geodetic data? The JMA-determined hypocenters are located off the modeled fault plane by approximately $0.05^{\circ}$ westward (Fig. 3c). On the other hand, the estimated error, with $2-\sigma(\sim 95 \%$ confidence level) in longitude, is $0.04^{\circ}$ (Table 1 ). Although this difference may be within the range of statistical error, predicted displacements cannot explain some points when slip apparently occurred at the location of the aftershocks. To address this, Additional files 5, 6: Figs. S4 and S5 show the results obtained from the uniform slip fault modeling, in which we shifted the best solution fault plane (Table 1) westward so as to fit to the aftershock distribution while maintaining the dip angle $\left(74^{\circ}\right)$, and searched other fault parameters in the same manner. We found that larger residuals remained (Additional file 5: Fig. S4) than the best model (Additional file 2: Fig. S1). Furthermore, uplift is predicted at GNSS site 950132, which is the opposite of what was observed (Additional file 6: Fig. S5). Thus, we can say that the geodetically estimated main slip area is significantly more toward the east

Table 1 Fault parameters for a fault model with a uniform slip. The location of the fault is indicated in the top-left corner

\begin{tabular}{llllllllll}
\hline Lon $\left({ }^{\circ}\right)$ & Lat $\left({ }^{\circ}\right)$ & Depth $(\mathbf{k m})$ & Length $(\mathbf{m})$ & Width $(\mathbf{k m})$ & Strike $\left({ }^{\circ}\right)$ & Dip $\left({ }^{\circ}\right)$ & Rake $\left({ }^{\circ}\right)$ & Slip $(\mathbf{m})$ & $\boldsymbol{M}_{\mathbf{w}}$ \\
\hline $141.976(0.021)$ & $42.586(0.017)$ & $16.2(1.7)$ & $14.0(3.9)$ & $15.9(3.5)$ & $358(3.5)$ & $74(4.4)$ & $113(7.2)$ & $1.3(0.4)$ & 6.56
\end{tabular}

Numbers in parentheses are the standard deviations $(1-\sigma)$ 


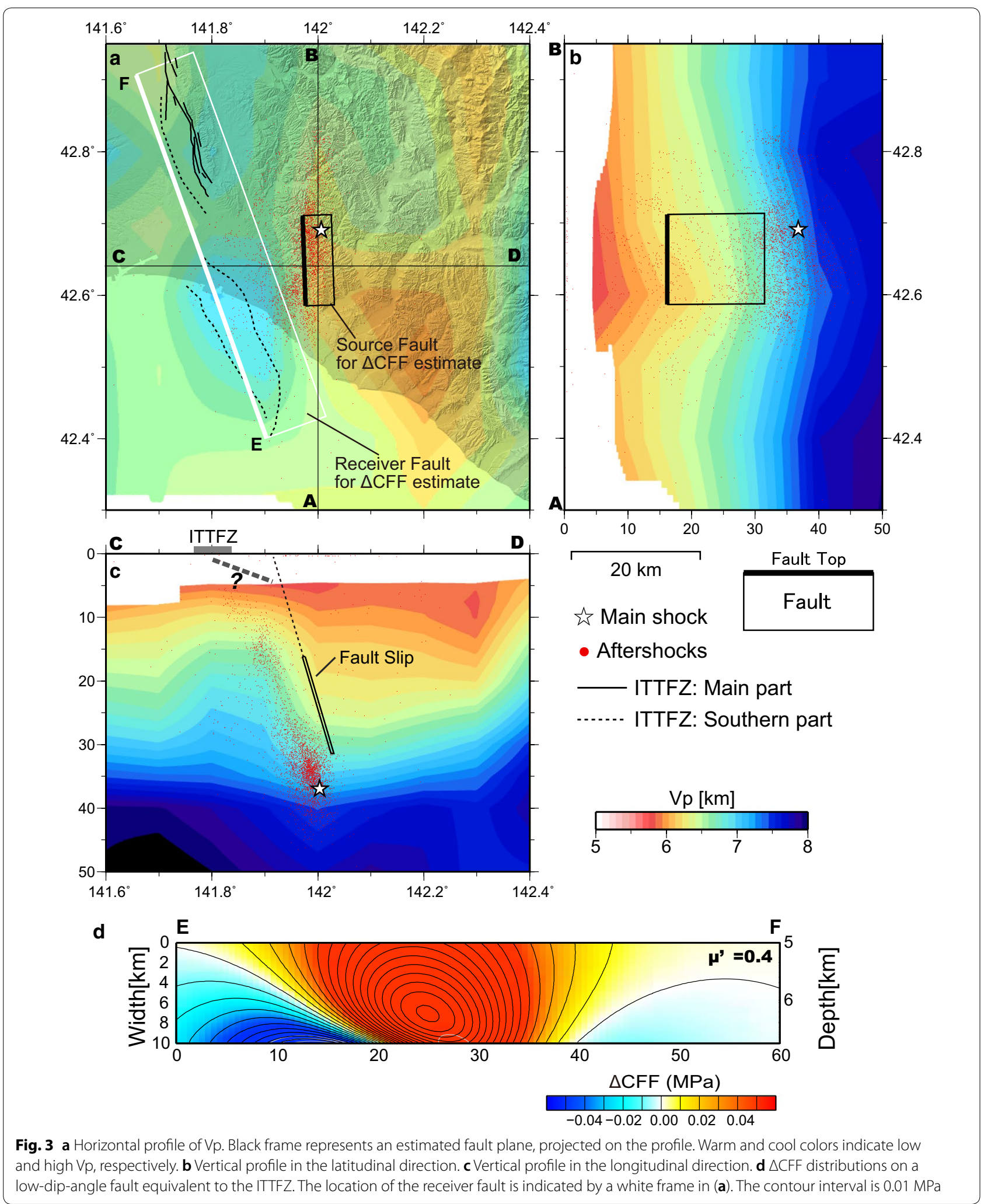


than the JMA-determined hypocenters would indicate. This discrepancy between the geodetic and the seismological results may result from this region's complicated crustal structure. It is vital for future studies to investigate what produces the differences between the results.

The estimated fault plane has a high dip angle $\left(74^{\circ}\right)$. If the fault plane extends to the ground surface with the same dip angle, the fault top would be located to the east of the known fault traces of the ITTFZ, suggesting that the fault plane for this event does not directly connect to the ITTFZ. One possibility is that the fault plane for the 2018 event is physically separate from the ITTFZ and the ITTFZ was not involved at all in the 2018 event. On the other hand, according to seismic surveys, there are some reflection planes with low angles at shallow depths in the ITTFZ (HERP 2010). If we assume both the fault that caused the 2018 event and the known ITTFZ are part of one fault system, the dip angle should turn out to be lower at shallow depth for the fault that caused the 2018 event (Fig. 3c). In this study, we claim only that this speculation is not inconsistent with the limited available data/knowledge, and it seems geophysically and geologically reasonable for the region. The fault slip terminated at approximately $\sim 15 \mathrm{~km}$ in depth, and thus it is difficult to exploit further information regarding fault structure from geodetic data. To deepen the discussion of this topic, more detailed information on regional crustal structures is needed in the future.

\section{Comparison to velocity structure}

Seismic surveys have revealed that earthquakes often occur at anomalous area of seismic velocity (e.g., Kato 2013). Also, in the Hidaka collision zone, large historical intraplate earthquakes occurred in and around anomalous velocity areas (Kita et al. 2012). Thus, it is possible that there is some relationship between the 2018 event and crustal structure. We examined the velocity structure in and around the source region. Figure $3 \mathrm{a}-\mathrm{c}$ shows the spatial distribution of P-wave (Vp) speed (Matsubara and Obara 2011; Matsubara et al. 2017). These profiles cut through the central part of the estimated fault model. A black-colored frame projected on each profile represents the fault plane. First, we find that the low and high $\mathrm{Vp}$ areas are distributed on the eastern and western sides of the source region, respectively (Fig. 3a). In the vertical profile in the longitudinal direction (Fig. 3c), the low $\mathrm{Vp}$ area thickens on the eastern side of the fault, and the fault slip is positioned at the western edge of the low Vp. It is noted that the Vp-stratified structure is tilted downward to the east at and around the fault, and it is consistent with the dip angle of the estimated fault plane. Also, when compared to the $\mathrm{Vp} / \mathrm{Vs}$ ratio (Additional file 7 : Fig. S6), we identify that low $\mathrm{Vp} / \mathrm{Vs}$ is distributed on the eastern side of the slip area, which may suggest involvement of water/fluid (Nakajima et al. 2001). The anomalous structure may suggest that the 2018 seismic event occurred at seismic velocity boundary.

Hypocenter estimate, in general, could be strongly by local structures (e.g., Melgar et al. 2018). The seismic velocity contrast indicates a shear modulus change across the fault. The lower shear modulus on the east side may push the hypocenters further to the west, which culminates in the above-mentioned spatial inconsistency between the geodetically and the seismically determined positions.

\section{Effect of stress change on the ITTFZ}

The crust in the proximity of the ruptured fault should have been subjected to a strong stress change during the 2018 event, which presumably culminated in the promotion of other earthquakes. To test this idea quantitatively, we evaluated Coulomb Failure Function change $(\triangle C F F)$ values (King et al. 1994). We assumed a receiver fault with a reverse motion on a fault plane dipping to the east with the dip angle of $10^{\circ}$ (HERP 2010). We placed a receiver fault along the ITTFZ with a strike of $340^{\circ}$, which is measured clockwise from north, at a fault top depth of $5 \mathrm{~km}$, indicated by the white frame in Fig. $3 \mathrm{a}$. Figure $3 \mathrm{~d}$ shows the $\triangle \mathrm{CFF}$ estimates. Warm and cool colors represent positive and negative signs, indicating facilitated or suppressed fault slip, respectively. We set an effective coefficient of friction $\mu$ of 0.4. In most regions of the ITTFZ-S, the $\triangle \mathrm{CFF}$ values tend to be positive. On the other hand, at the southern and northern tips of the ITTFZ-S, the $\triangle$ CFF values are negative. We attempted to evaluate the stability of our stress change pattern for an effective coefficient of friction from 0.2 to 0.8 , and confirmed that in all cases the spatial patterns are substantially the same (Additional file 8: Fig. S7b, e, h). In addition, we evaluated the stability for a fault top depth from 0 to $10 \mathrm{~km}$. In all cases, reverse slip tends to be promoted in the central part of the ITTFZ-S, while in the northern and southern tips of the ITTFZ-S, the promotion/suppression of slip is sensitive to fault depth. At this stage, we can say at least that the slip could be promoted on the central part of the ITTFZ. Of course, care must be taken with these estimates because the source and the receiver faults are close together, and thus our estimates can be sensitive to position and the given slip mechanism. To evaluate it more thoroughly, more detailed locations and fault geometries of the ITTFZ will be needed.

\section{Conclusions}

By applying the InSAR method to ALOS-2 data, we have mapped the crustal deformation associated with the 2018 Hokkaido Eastern Iburi earthquake and obtained 
the source properties. The following conclusions were derived from our analyses.

1. Uplift of up to $\sim 7 \mathrm{~cm}$ is predominantly distributed in the source region, and eastward movement of up to $\sim \mathrm{cm}$ is widely observed on the eastern side of the source region.

2. The fault model shows that the fault plane extends in a north-south direction and is dipping to the east with a dip angle of $74^{\circ}$. The fault plane has a relatively high dip angle, and the shallow extension of the estimated fault plane does not directly connect to any known surface traces of the ITTFZ.

3. The fault model shows a reverse fault motion with a $M_{\mathrm{w}}$ 6.6. The fault top is positioned at around $15 \mathrm{~km}$ in depth, suggesting that the slip significantly occurs deeper than the typical seismogenic zone for the Japanese island $(\sim 15 \mathrm{~km})$.

4. The estimated fault is located in a region of anomalous seismic velocity, possibly suggesting that the 2018 earthquake occurred at seismic velocity boundary.

5. A $\triangle \mathrm{CFF}$ estimate suggests that the static stress change due to the Eastern Iburi earthquake can promote reverse slip in the central region of the ITTFZS. For the northern and southern tip of the ITTFZ-S, slip can be suppressed in some cases due to sensitivity to fault depth.

\section{Additional files}

Additional file 1: Table S1. Analyzed ALOS-2 images. "Bp" means a perpendicular baseline. The flight direction is measured clockwise from the north

Additional file 2: Fig. S1. (a) InSAR-derived deformation map for path 18 (b) LOS displacement field calculated from the fault model with a uniform slip. (c) Residual between the observations and the calculation. (d)-(f) Same as (a) but for path 116. (g)-(i) Same as (a) but for path 122.

Additional file 3: Fig. S2. Enlarged view of the QUD map in and around GNSS site 950141.

Additional file 4: Fig. S3. Variation of fault parameter estimates obtained from a bootstrap approach. Longitude and latitude are center position of fault plane, while depth is fault top position.

Additional file 5: Fig. S4. Same as Fig. S1 but for calculations from the fault model fitted to aftershock distribution.

Additional file 6: Fig. S5. GNSS data fitting for the fault model fitted to aftershock distribution

Additional file 7: Fig. S6. Vp/Ns ratio plotted in the same manner as Fig. 3.

Additional file 8: Fig. S7. $\triangle C F F$ distribution on a receiver fault. (a) $\triangle C F F$ for $\mu=0.2$ and a fault top of $0 \mathrm{~km}$. (b) Same as (a) but for a fault top of $5 \mathrm{~km}$. (c) Same as (a) but for a fault top of $10 \mathrm{~km}$. (d)-(f) Same as (a)-(c) but for $\mu=0.4$. (g)-(i) Same as (a)-(c) but for $\mu=0.8$

\section{Acknowledgements}

ALOS-2 data were provided by the Earthquake Working Group under a cooperative research contract with Japan Aerospace Exploration Agency (JAXA). The ownership of ALOS-2 data belongs to JAXA. We used the software "Hi-net 3D Tomography Viewer (Ver. 3.0)" to plot the velocity structure. Hypocenter data processed by the Japan Meteorological Agency (JMA) were used. Generic Mapping Tools (GMT) (Wessel and Smith 1998) were used to construct the figures.

\section{Authors' contributions}

TK analyzed the InSAR data, constructed the fault models, and drafted the manuscript. KH produced the InSAR data. HY discussed the results and managed the study. All authors read and approved the final manuscript.

\section{Funding}

Not applicable.

Availability of data and materials

The product data obtained in this study are available by contacting the corresponding author directly.

\section{Competing interests}

The authors declare that they have no competing interests.

Received: 6 March 2019 Accepted: 22 May 2019

Published online: 31 May 2019

\section{References}

Fujiwara S, Tobita M (1999) SAR interferometry techniques for precise surface change detection. J Geod Soc Jpn 45:283-295 (in Japanese with English abstract)

Fujiwara S, Tobita M, Murakami M, Nakagawa H, Rosen PA (1999) Baselinedetermination and correction of atmospheric delay induced by topography of SAR interferometry for precise surface change detection. J Geod Soc Jpn 45:315-325 (in Japanese with English abstract)

Fujiwara S, Nishimura T, Murakami M, Nakagawa H, Tobita M, Rosen PA (2000) 2.5-D surface deformation of a M6.1 earthquake near Mt Iwate detected by SARInterferometry. Geophys Res Lett 27:2049-2052

Fujiwara S, Nakano T, Morishita Y, Kobayashi T, Yarai H, Une H, Hayashi K (2019) Detection and interpretation of local surface deformation from the 2018 Hokkaido Eastern Iburi earthquake using ALOS-2 SAR data. Earth Planets Space. https://doi.org/10.1186/s40623-019-1046-2

Gomba G, Parizzi A, De Zan F, Eineder M, Bamler R (2016) Toward operationalcompensation of ionospheric effects in SAR interferograms: The splitspectrum method. IEEE Trans Geosci Remote Sens 54(3):1446-1461. https //doi.org/10.1109/TGRS.2015.2481079

Headquarters for Earthquake Research Promotion (2010) Evaluation of active faults to date. https://www.jishin.go.jp/main/chousa/katsudanso u_pdf/06_ishikari-teichi_2.pdf (in Japanese)

Headquarters for Earthquake Research Promotion (2018) Evaluation of the 2018 Hokkaido Eastern Iburi earthquake. https://www.jishin.go.jp/ main/chousa/18oct_iburi/index-e.htm. Accessed 20 February 2019 (in Japanese)

Himematsu Y, Furuya M (2016) Fault source model for the 2016 Kumamoto earthquake sequence based on ALOS-2/PALSAR-2 pixel-offset data: evidence for dynamic slip partitioning. Earth Planets Space 68(1):169. https ://doi.org/10.1186/s40623-016-0545-7

Ito T (2002) Active faulting, lower crustal delamination and ongoing Hidaka arc-arc collision, Hokkaido, Japan. In: By Fujinawa Y, Yoshida A (eds) Seismotectonics in convergent plate boundary. TERRAPUB, Tokyo, pp 219-224

Iwasaki T, Adachi K, Moriya T, Miyamachi H, Matsushima T, Miyashita K, Takeda T, Taira T, Yamada T, Ohtake K (2004) Upper and middle crustal deformation of an arc-arc collision across Hokkaido, Japan, inferred from seismic refraction/wide-angle reflection experiments. Tectonophysics 388:59-73. https://doi.org/10.1016/j.tecto.2004.03.025

Japan Meteorological Agency (2018a) Focal mechanism catalog using initial motion. http://www.data.jma.go.jp/svd/eqev/data/mech/ini/mc201809. html. Accessed 15 February 2019 (in Japanese) 
Japan Meteorological Agency (2018b) CMT catalog. http://www.data.jma. go.jp/svd/eqev/data/mech/cmt/cmt201809.html. Accessed 15 February 2019 (in Japanese)

Kato A (2013) Imaging the source regions of normal faulting sequences induced by the 2011 M9.0 Tohoku-Oki earthquake. Geophys Res Lett 40:273-278. https://doi.org/10.1002/grl.50104

Kimura G (1986) Oblique subduction and collision: Forearc tectonics of the Kuril Arc. Geology 14:404-407

King GCP, Stein RS, Lin J (1994) Static stress changes and the triggering of earthquakes. Bull Seismol Soc Am 84:935-953

Kita S, Hasegawa A, Nakajima J, Okada T, Matsuzawa T, Katsumata K (2012) High-resolution seismic velocity structure beneath the Hokkaido corner, northern Japan: arc-arc collision and origins of the 1970 M 6.7 Hidaka and 1982 M 7.1 Urakawa-oki earthquakes. J Geophys Res 171:B12301

Kobayashi T (2016) Effect of Atmospheric-related noise reduction using numerical weather model for InSAR analysis: application to the 2015 Sakurajima dike intrusion event. J Geol Soc Jpn 62:79-88. https://doi. org/10.11366/sokuchi.62.79 (in Japanese with English abstract)

Kobayashi T (2017) Earthquake rupture properties of the 2016 Kumamoto Earthquake foreshocks (M;6.5 and M.6.4) revealed by conventional and multiple-aperture InSAR. Earth Planets Space 69(1):7. https://doi. org/10.1186/s40623-016-0594-y

Kobayashi T, Tobita M, Koarai M, Okatani T, Suzuki A, Noguchi Y, Yamanaka M, Miyahara B (2012) InSAR-derived crustal deformation and fault models of normal faulting earthquake $\left(M_{\mathrm{j}} 7.0\right)$ in Fukushima-Hamadori area. Earth Planets Space 64(12):1209-1221. https://doi.org/10.5047/eps.2012.08.015

Kobayashi T, Ishimoto M, Tobita M, Yarai H (2014) A tool for reduction of atmosphere-related noises included in an InSAR image, incorporating a numerical weather model. Bull GSI 125:31-38 (in Japanese)

Kobayashi T, Morishita Y, Yarai H (2017) SAR-revealed slip partitioning on a bending fault plane for the 2014 Northern Nagano earthquake at the northern Itoigawa-Shizuoka tectonic line. Tectonophysics 733(9):85-99. https://doi.org/10.1016/j.tecto.2017.12.001

Matsubara M, Obara K (2011) The 2011 off the pacific coast of Tohoku earthquake related to a strong velocity gradient with the Pacific plate. Earth Planets Space 63(7):663-667. https://doi.org/10.5047/eps.2011.05.018
Matsubara M, Sato H, Uehira K, Mochizuki M, Kanazawa T (2017) Threedimensional seismic velocity structure beneath Japanese Islands and surroundings based on NIED seismic networks using both inland and offshore events. J Disaster Res 12:844-857. https://doi.org/10.20965/ jdr.2017.p0844

Melgar D, Ruiz-Angulo A, Garcia ES, Manea M, Manea VC, Xu X, Ramirez-Herrera T, Zavala-Hidalgo J, Geng J, Corona N, Pérez-Campos X, Cabral-Cano E, Ramirez-Guzmán L (2018) Deep embrittlement and complete rupture of the lithosphere during the Mw 8.2 Tehuantepec earthquake. Nat Geosci 11:955-960. https://doi.org/10.1038/s41561-018-0229-y

Nakajima J, Matsuzawa T, Hasegawa A, Zhao D (2001) Three-dimensional structure of $V p, V s$, and $V p / V s$ beneath northeastern Japan: implications for arc magmatism and fluids. J Geophys Res 106:21843-21857

Okada Y (1985) Surface deformation due to shear and tensile faults in a halfspace. Bull Seismol Soc Am 75:1135-1154

Rosen P, Hensley S, Chen C (2010) Measurement and mitigation of the ionosphere in L-band Interferometric SAR data. In: Proc IEEE Radar Conf. https ://doi.org/10.1109/radar.2010.5494385

Terakawa T, Matsu'ura M (2010) The 3-D tectonic stress fields in and around Japan inverted from centroid moment tensor data of seismic events. Tectonics 29:TC6008. https://doi.org/10.1029/2009TC002626

Tobita M (2003) Development of SAR interferometry analysis and its application to crustal deformation study. J Geod Soc Jpn 49:1-23 (in Japanese with English abstract)

Tobita M, Fujiwara S, Murakami M, Nakagawa H, Rosen PA (1999) Accurate offset estimation between two SLC images for SAR interferometry. J Geod Soc Jpn 45:297-314 (in Japanese with English abstract)

Wessel P, Smith WH (1998) New, improved version of Generic Mapping Tools released. EOS Trans AGU 79:579

\section{Publisher's Note}

Springer Nature remains neutral with regard to jurisdictional claims in published maps and institutional affiliations.

\section{Submit your manuscript to a SpringerOpen ${ }^{\odot}$ journal and benefit from:}

- Convenient online submission

- Rigorous peer review

- Open access: articles freely available online

- High visibility within the field

- Retaining the copyright to your article

Submit your next manuscript at $\boldsymbol{\nabla}$ springeropen.com 